\title{
Prevalence and Characteristics of Borderline Intellectual Functioning in a Cohort of Patients With Polysubstance Use Disorder
}

\author{
Jens Hetland ${ }^{1,2 *}$, Kirsten J. Braatveit ${ }^{3,4}$, Egon Hagen ${ }^{1}$, Astri J. Lundervold ${ }^{2}$ and \\ Aleksander H. Erga ${ }^{1,2,5}$
}

${ }^{1}$ KORFOR - Center of Alcohol and Drug Research, Division of Psychiatry, Stavanger University Hospital, Stavanger, Norway, ${ }^{2}$ Department of Biological and Medical Psychology, University of Bergen, Bergen, Norway, ${ }^{3}$ Department of Research and Innovation, Helse Fonna HF, Haugesund, Norway, ${ }^{4}$ Haugaland A-senter, Blue Cross Norway, Haugesund, Norway, ${ }^{5}$ The Norwegian Center for Movement Disorders, Stavanger University Hospital, Stavanger, Norway

\section{OPEN ACCESS}

Edited by: Maximilian Pilhatsch,

Technical University of

Dresden, Germany

Reviewed by:

Maik Spreer

Technische Universität

Dresden, Germany

Frederik Haarig,

Rudolf Virchow Glauchau

Clinic, Germany

*Correspondence: Jens Hetland

jens.hetland@sus.no

Specialty section:

This article was submitted to

Addictive Disorders,

a section of the journal

Frontiers in Psychiatry

Received: 08 January 2021 Accepted: 21 June 2021 Published: 14 July 2021

Citation:

Hetland J, Braatveit KJ, Hagen E, Lundervold AJ and Erga AH (2021)

Prevalence and Characteristics of

Borderline Intellectual Functioning in a

Cohort of Patients With

Polysubstance Use Disorder.

Front. Psychiatry 12:651028.

doi: 10.3389/fpsyt.2021.651028
Objective: To determine the prevalence and associated demographic and clinical features of borderline intellectual functioning (BIF) among individuals with polysubstance use disorder (pSUD).

Methods: We applied a cross-sectional analytical design to data from the Norwegian STAYER study ( $n=162$ ), a cohort study of patients with a pSUD from the Stavanger University hospital catchment area. We used Wechsler Abbreviated Scale of Intelligence Full Scale IQ (FSIQ) to define BIF (FSIQ = 70-85) and non-BIF (FSIQ = >85) and collected demographic and clinical data using semi-structured interviews and self-reports on the Symptom Checklist 90-Revised (SCL-90-R) and the Satisfaction With Life Scale (SWLS).

Results: The prevalence of BIF was $18 \%$ in the present study. The presence of BIF was associated with higher SCL-90-R GSI scores than in the non-BIF group. There were no significant differences between the BIF and non-BIF groups regarding age, gender, participation in meaningful daily activity, years of work experience, years of education, satisfaction with life, level of care, treatment attempts, age at substance-use onset, years of substance use, history of injecting drugs, or age of onset of injecting drugs.

Conclusion: The present study confirmed a higher prevalence of BIF among patients with pSUD than expected from the distribution of $I Q$ scores in a general population. Elevated SCL-90-R GSI scores suggested that BIF is associated with increased psychological distress in patients receiving treatment for pSUD. Further studies on this association, and its effect on treatment procedure and outcomes are strongly warranted.

Keywords: polysubstance use disorder, borderline intellectual functioning, symptom check list-90-R, satisfaction with life scale, intelligence quotient, prevalence, substance use disorder

\section{INTRODUCTION}

Intellectual functioning in patients with substance use and abuse has received increased attention during the last decade $(1,2)$. This follows the fact that intellectual functioning (e.g., reasoning, planning, problem solving, judgement, and abstract thinking) is a core predictor of a variety of life outcomes, with the most severe impairments observed in patients with an intelligence quotient 
(IQ) two standard deviations below the population mean (IQ $<70)(3-5)$. In the present study, we focused on the impact of borderline intellectual functioning (BIF), which is defined as an intelligence quotient ranging between one and two standard deviations below the population mean (IQ $=70-85$ ). Based on previous studies, we know that adults with BIF have an increased vulnerability for developing psychiatric disorders, including a substance use disorder (SUD) (2, 6-12). Assessment of intellectual function should therefore be considered an important component of clinical examination and treatment planning of SUDs.

According to the normal distribution of IQ scores (Bell Curve), approximately $13.6 \%$ of individuals in the general population would be allocated to a subgroup defined with BIF, with elevated rates commonly observed in clinical populations (13). Nevertheless, the frequency estimates within clinical groups are uncertain because of methodological differences between studies (ascertainment biases, the choice of diagnostic tools, service configurations, and entry criteria). In addition, there is a historical lack of terminological consensus and classification of $\operatorname{BIF}(14,15)$ and non-agreed-upon diagnostic criteria in diagnostic manuals like the DSM-V and ICD-10 $(16,17)$. Nevertheless, studies have shown that individuals with BIF exhibit difficulties in several aspects of life, that these difficulties may occur at a similar level as for individuals with a diagnoses of intellectual disability (ID), and that individuals with BIF may need targeted support $(1,4,6,9,10,14,18-21)$.

Individuals with BIF may not only be severely impaired; they are also less likely to receive adequate treatment for mental health issues, less likely to receive psychotherapy, and more likely to be treated with psychotropic medication than individuals with mental health problems in the general population $(10,22)$. This is obviously the case in individuals with co-occurring BIF and SUD; they tend to show adverse rehabilitation outcomes when offered mainstream SUD treatment, because of factors such as reduced disposition to change and desire for help $(23,24)$, lower treatment compliance (25), high drop-out rate (26-28), relapse during treatment (29), and negative treatment experiences (30). Therefore, it is alarming to realize that impaired intellectual functioning is often overlooked in treatment programs for patients with SUD, even though it can be a key clinical factor in predicting treatment needs and prognosis $(24,29,31-34)$.

There is a dearth of research on BIF in general, and BIF in SUD populations in particular. When included in studies, BIF is typically classified broadly as mild-to-borderline intellectual disability (MBID) with IQ ranging between 50 and 85, or treated as a control group (4). The major thrust of research on the co-occurrence of BIF and SUD originate from the field of ID services and target substance use in individuals with a known ID diagnosis. Subsequently, findings are mainly published in journals in that field, rather than in journals in the field of medical addiction (2). Initiatives to develop a framework around the clinical and adaptive needs of patients with co-occurring SUD and BIF have been sporadic and uncoordinated (14).

Studies examining the prevalence rates of BIF in SUD populations are scarce, and their prevalence rates vary considerably. Braatveit et al. found the prevalence rate of
BIF among patients with SUD to be 23\% (29), and Luteijn et al. reported a MBID prevalence rate of 39\% (24). At the other end of the scale, VanDerNagel et al. reported a prevalence estimate as low as 3\% (35). Furthermore, prevalence data for BIF and MBID are difficult to compare because of lack of consensus on terminology, differences in group characteristics, levels of disability, treatment settings, comorbid psychiatric disorders, and definition and scope of substance use $(2,13,36)$. Taken together, studies of BIF based on standard instruments in well-characterized cohorts of patients with SUD are obviously warranted.

The lack of epidemiological data and findings showing that BIF may be vital for the broader understanding and treatment of patients with SUD motivated the present study to investigate the prevalence and characteristics of patients with BIF in a typical group of individuals receiving treatment for polysubstance use disorder (pSUD). Polysubstance use is common in both clinical, and population samples $(37,38)$. Moreover, polysubstance use patterns is frequent in patients seeking treatment for monosubstance disorders (39-43). In this context, pSUD refers to the use of multiple substances as part of a pattern of problematic substance use, in which the patient meets criteria for SUD for some, but not necessarily all substances used (44). Compared with mono-substance users, polysubstance users have an earlier onset of substance use (45), are younger (37), have higher levels of psychological distress and personality disorders (4550), more persistent cognitive impairments (51), and poorer social adjustment $(37,46,48,52)$. Studies suggest that these characteristics are associated with increased risk of dropout and relapse $(27,53-57)$. Thus, patients with pSUD may have a more severe clinical profile than patients with mono-substance use and consequently pose a challenge for SUD-treatment services and the mental health care system $(46,53,58,59)$.

The aim of the present study is twofold: (1) to provide a prevalence estimate of BIF in patients with pSUD receiving mainstream SUD treatment (2) to investigate clinical and demographic features in subgroups of patients with and without co-existing BIF.

\section{MATERIALS AND METHODS}

\section{Study Design and Patient Characteristics}

The study used data from the Stavanger Study of Trajectories of Addiction (STAYER), an ongoing, prospective, longitudinal cohort study of the neurocognitive, psychological and social recovery in patients with polysubstance use who started a new treatment sequence in the Stavanger University Hospital catchment area $(60,61)$. See Andersson et al. (54) for more details regarding the structure of Norwegian SUD-treatment. To be eligible for specialized treatment for SUDs within the Norwegian public health service, patients must meet the criteria for a F1x.1 (harmful use) or F1x.2 (dependency syndrome) diagnosis, as defined by the ICD-10 (17). We performed baseline assessment after 2 weeks of abstinence, in an attempt to minimize contamination from drug withdrawal and the acute neurotoxic effects from psychoactive substances (62). Trained research personnel of the STAYER research group collected all data. In the 
present study, polysubstance users were defined as patients with SUD who reported the use of multiple substances within the last year before inclusion. The project was approved by the Regional Ethics Committee (REK 2011/1877) and conducted according to its guidelines and those of the Helsinki Declaration (1975). All participants provided signed informed consent.

\section{Participants}

A total of 208 patients were recruited consecutively at convenience from 10 outpatient and residential treatment facilities within the Stavanger University Hospital catchment area between March 2012 and January 2016. All patients had been voluntary admitted for SUD-treatment.

Patients were included if they (1) signed a written informed consent, (2) were enrolled in a new rehabilitation sequence by the substance use treatment service, (3) reported use of multiple substances within the last year before inclusion, and (4) were 16 years or above. Patients received a compensation of NOK 400 for their time at the baseline testing. Of the 208 patients in the STAYER cohort, 44 patients were excluded from the present study because of mono-substance use (alcohol $N=35$, cannabis $N$ $=1$ ) or lack of substance-related disorders (e.g., gambling $N=$ 8 ). We excluded one case because of missing IQ scores and one case because of an IQ score $<70$; thus, the remaining sample of patients with pSUD comprised 162 individuals.

\section{Assessment}

We obtained demographic, neurocognitive, psychological, and social-functioning data using semi-structured interviews, cognitive tests, and self-reported measures at the baseline assessment. We used a preliminary version of the National Quality Register for Substance Abuse (KVARUS) (63), a semistructured interview to obtain information on the type of substance intake, initial age at use, treatment and work history, and educational, vocational, and social adjustment.

\section{Wechsler Abbreviated Scale of Intelligence}

Wechsler Abbreviated Scale of Intelligence (WASI) (64) was used to assess intellectual function. WASI was created to establish a brief and reliable estimate of intellectual functioning and comprises four subtests, i.e., two verbal measures of crystalized intelligence (Vocabulary and Similarities), which yield a verbal intelligence quotient (VIQ), and two non-verbal tests of fluent intelligence (Block Design and Matrix Reasoning), which yield a performance intelligence quotient (PIQ). BIF was defined as a WASI Full-scale IQ (FSIQ) ranging between 70 and 85, and non-BIF was defined as a FSIQ $>85$.

\section{Satisfaction With Life Scale}

Satisfaction with life was assessed using the Satisfaction With Life Scale (SWLS) (65). SWLS is a self-report questionnaire comprising five items to measure the respondent's global life satisfaction with a seven-point Likert-type format (ranging from 1 -strongly disagree to 7-strongly agree). SWLS has demonstrated excellent psychometric characteristics (66) and also validated for individuals with ID (Cronbach's alpha $=0.79)(67)$. A score of 20 represents a neutral point on the scale; scores between 5 and 9 indicate dissatisfaction with life, while scores ranging between 31 and 35 indicate that the respondent is very satisfied with life (66).

\section{Symptom Checklist 90-Revised}

We used the Symptom Checklist 90-Revised (SCL-90-R), which is a 90-item self-report measure (68) assessing psychological symptoms and distress. SCL-90-R is widely used in clinical practice and research, and validated for patients with SUD and individuals with ID (68-70). Items are rated on a fivepoint Likert scale indicating the degree of distress, ranging from 0 (not at all) to 4 (severely) during the 7 previous days. The checklist comprises nine symptom dimension subscales: Somatization, Obsessive-Compulsive Disorder, Interpersonal Sensitivity, Depression, Anxiety, Hostility, Phobic Anxiety, Paranoid Ideation, and Psychoticism, in addition to a global severity index (GSI), which was used here as a measure of psychological distress.

\section{Statistics}

The statistical software package SPSS version 26 (IBM Corp., released 2016) was used for all statistical analyses. Statistical significance was set at $P<0.05$, and assumptions of normality evaluated based on $\mathrm{Q}-\mathrm{Q}$ plots and by inspecting the residuals. A frequency analysis was run for the BIF and non-BIF groups. Independent-sample $t$-tests were performed to evaluate differences between-group means, and the chi-squared test of independence was used in case of categorical variables.

Because of an association between BIF status and SCL-90-R GSI score, we performed additional post hoc analyses to explore this association. As a result of the modest size of the BIF group, we opted not to use BIF status as a dependent variable in logistic regression analyses because of the risk of overfitting the regression model (71). Instead, we performed a multiple regression analysis (forward selection) with SCL-90-R GSI score as the dependent variable and BIF status, age, gender, years of education, age of onset of substance use, history of injecting drugs, and SWLS sum score as independent variables.

\section{RESULTS}

Among the 162 participants included in the analyses, 29 (17.9\%) were classified as having BIF. Table 1 shows the demographic and clinical features in the total sample and stratified according to intellectual functioning (i.e., the BIF and non-BIF group). Participants in the BIF group $(\mathrm{M}=1.4, \mathrm{SD}=0.8)$ exhibited significantly higher SCL-90-R GSI scores than the non- BIF group $\left[\mathrm{M}=1.1, \mathrm{SD}=0.6 ; t_{(160)}=2.5, p<0.05\right]$, indicating a higher degree of self-reported psychological distress in the former group. No further significant differences were detected between the BIF and non-BIF groups on any demographic or clinical feature.

Figure 1 shows that the distribution of IQ scores in the present cohort was comparable to the expected distribution in the general population, with a small shift toward the lower end of the scale.

Table 2 lists the WASI scores in the total sample and within the two groups. The mean WASI FSIQ in this BIF group was 80.3 
TABLE 1 | Demographic and clinical features of the present sample stratified according to intellectual functioning.

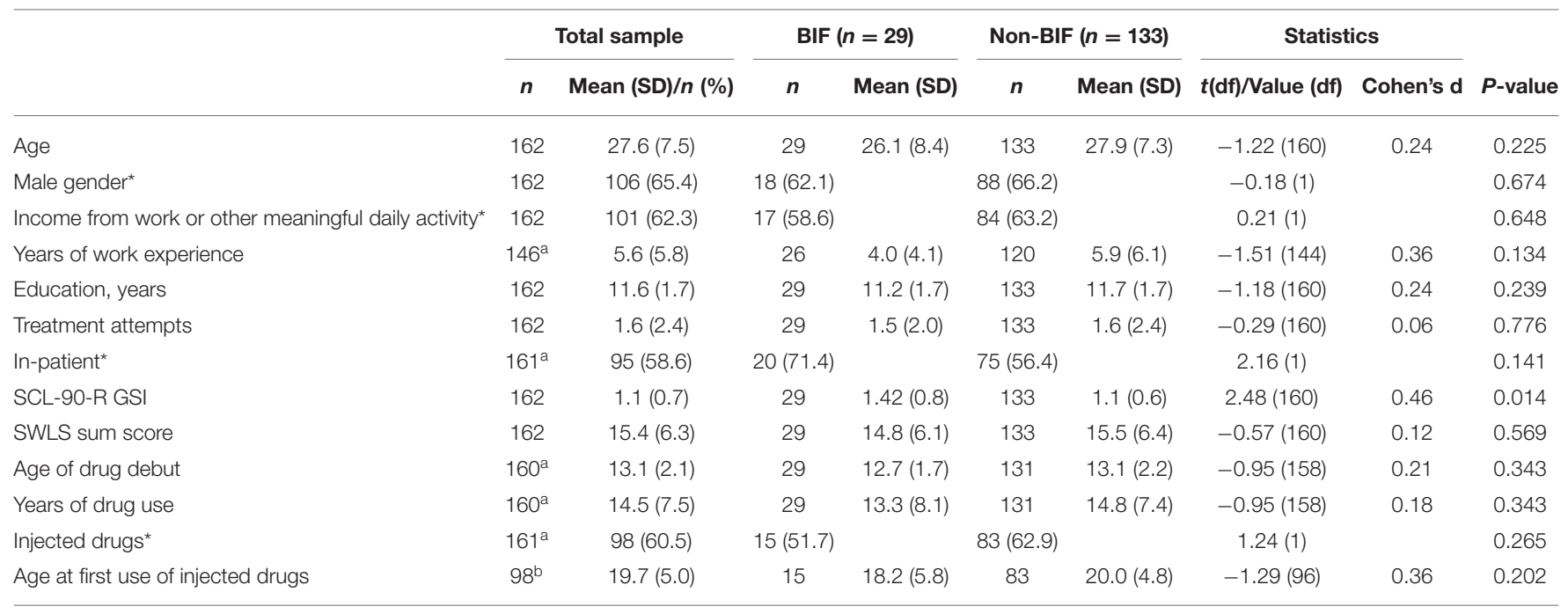

${ }^{*}$ Chi-squared test of independence.

a Numbers lower than 162 are caused by missing data.

${ }^{b}$ Participants with a history of injecting drugs.

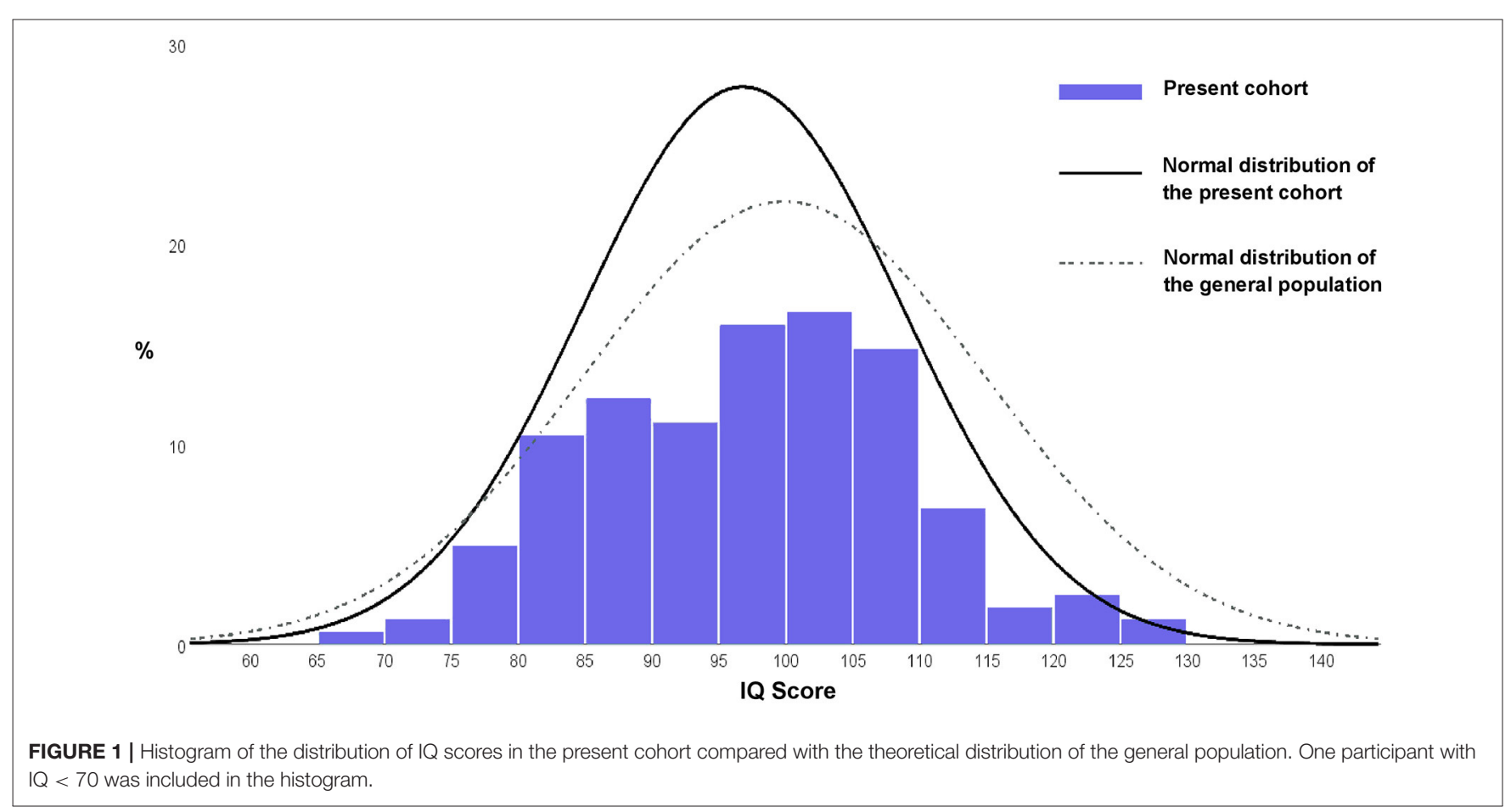

$(\mathrm{SD}=3.8,95 \% \mathrm{CI}=78.8-81.7)$, whereas the mean WASI FSIQ was $100.8(\mathrm{SD}=9.4,95 \% \mathrm{CI}=99.1-102.4)$ in the non-BIF group.

A multiple regression analysis using the SPSS' forward selection algorithm was computed to further investigate the association between the presence of BIF and the SCL-90-R GSI scores. The SCL-90-R GSI scores were included as the dependent variable and the BIF status as well as age, gender, years of education, age of onset of substance use, history of injecting drugs, and SWLS sum score as independent variables. This procedure yielded a significant regression equation $\mathrm{F}_{(3,156)}=$ $\left.14.882, P<0.001 ; R^{2}=0.223\right)$, leaving BIF status as well as age, and SWLS sum score as significant predictors of the SCL-90-R GSI scores (see Table 3 for details).

\section{DISCUSSION}

The prevalence rate of BIF in patients with polysubstance use was $18 \%$ in the present study. There were few statistically significant 
TABLE 2 | WASI scores in the total sample stratified according to intellectual functioning.

\begin{tabular}{|c|c|c|c|c|c|c|c|c|c|}
\hline & \multicolumn{2}{|c|}{ Total sample } & \multicolumn{2}{|c|}{ BIF $(n=29)$} & \multicolumn{2}{|c|}{ Non-BIF $(n=133)$} & \multicolumn{2}{|c|}{ Statistics } & \multirow[b]{2}{*}{$P$ value } \\
\hline & $n$ & Mean (SD) & $n$ & Mean (SD) & $n$ & Mean (SD) & $t(\mathrm{df})$ & d & \\
\hline WASI FSIQ & 162 & $97.1(11.7)$ & 29 & 80.3 (3.8) & 133 & $100.8(9.4)$ & $-11.5(160)$ & 2.85 & $<0.001$ \\
\hline WASI VIQ & 162 & $95.1(12.7)$ & 29 & $82.5(8.2)$ & 133 & 97.8 (11.8) & $-6.6(160)$ & 1.51 & $<0.001$ \\
\hline WASI PIQ & 162 & $99.9(13.2)$ & 29 & $82.0(8.1)$ & 133 & $103.8(10.7)$ & $-10.4(160)$ & 2.30 & $<0.001$ \\
\hline
\end{tabular}

TABLE 3 | Summary of the regression analysis with SCL-90-R GSI as dependent and BIF status, age, and SWLS sum as independent variables.

\begin{tabular}{llllll}
\hline Variable & $\mathbf{B}$ & $\mathbf{9 5 \%} \mathbf{~ I ~}$ & $\boldsymbol{\beta}$ & $\boldsymbol{t}$ & $\boldsymbol{p}$ \\
\hline (Constant) & 2.533 & {$[2.082,2.983]$} & & 11.106 & $<0.001$ \\
SWLS Sum score & -0.039 & {$[-0.054,-0.024]$} & -0.369 & -5.219 & $<0.001$ \\
Age & -0.021 & {$[-0.033,-0.008]$} & -0.233 & -3.283 & 0.001 \\
BIF-status & -0.256 & {$[-0.499,-0.014]$} & -0.148 & -2.086 & 0.039
\end{tabular}

BIF status is coded as 0 for BIF and as 1 for non-BIF.

$\mathrm{Cl}$, confidence interval for $\mathrm{B}$.

differences between the BIF and non-BIF groups regarding demographic and clinical features. However, patients with BIF had significantly elevated SCL-90-R GSI scores, indicating a higher degree of psychological distress compared with the nonBIF group. A regression analysis confirmed the importance of BIF status, even when controlling for a range of demographic and clinical data.

The prevalence rate of BIF found in the current study was higher than that observed in the general population, but still somewhat lower than reported by some previous studies of patients selected from in-patient SUD populations $(24,29)$. However, the sample included in the study of Luteijn et al. (24) was selected from a forensic unit and gauged the prevalence rate of MBID, not BIF. Although it may be tempting to hypothesize that patients receiving in-patient treatment have more impaired intellectual functioning compared to patients receiving outpatient treatment, the results of the current study do not support this notion, as there were no significant differences in the prevalence rate of BIF between these two groups. The prevalence rate of BIF found in the present study was indeed higher than the $3 \%$ identified by VanDerNagel et al. (35). However, those authors relied on the identification of individuals with BIF through a review of caseloads and patient records. Because of the low recognition of MBID/BIF, those findings are expected to provide underestimations compared with the results of studies including direct assessment of intellectual functioning.

The regression model indicated independent negative associations between the independent variables SWLS sum score, age, and BIF-status and SCL-90-R GSI score among patients with pSUD. The association between SWLS sum score and SCL-90-R GSI score was expected, given the conceptual similarities between psychological well-being and life satisfaction in human functioning. In addition, age was negatively associated with SCL-90-R GSI scores, a finding that was expected based on previous studies $(44,72)$. A strong association between BIF and an elevated SCL-90-R GSI score among patients suffering from pSUD is a main finding of the present study. This finding is in accordance with previous studies reporting associations between psychological distress and impaired intellectual functioning (19, 73-76). Although causality of the association between SCL-90-R GSI score and BIF status in the present study is unknown, several direct and indirect paths may be suggested.

Individuals with impaired intellectual functioning may be susceptible to the development of psychological ill-health and impaired social adjustment due to reduced capacity for problemsolving, flexible adjustment and stress tolerance (77). Conversely, psychiatric disorders may induce temporary state-specific neurocognitive disruptions impairing cognitive performance (78-80). Finally, the selected measures may not reflect disparities in latent cognitive abilities as psychological distress may impede test performance indirectly through lack of performance motivation, low self-efficacy and increased engagement in distracting worrisome thoughts or task-irrelevant cognition.

The use of an IQ criterion in the diagnosis of ID is thought to reflect a relationship between intellectual and everyday functioning, and most studies identify borderline intellectual disability solely from intellectual functioning measures, i.e., BIF (29). While the current study found disparities in the associated clinical features between the BIF and non-BIF patients with pSUD, the differences were primarily reserved to the SCL-90R GSI score. Surprisingly, the findings thus did not support the presence of a more global impairment in BIF compared to nonBIF patients with pSUD. e.g., educational attainment is typically shown to be associated with higher intellectual functioning (8183). However, to access specialized treatment for SUDs within the Norwegian public health service, patients must exhibit severely debilitating substance use. Furthermore, both the BIF, and nonBIF groups share approximately the same early onset of substance use (13 years). Both early onset and subsequent severe substance use likely attenuate the predictive value of IQ by exerting a major detrimental influence on scholastic performance (84), attendance (85), drop out (86-89), and overall social adjustment.

The present study used the classification of BIF rather than borderline intellectual disability, as the latter relies on additional measures of adaptive functioning and onset before 18 years of age. In addition, several studies investigated the clinical features of co-occurring BIF and SUD by combining the IQ ranges of BIF and mild ID $(2,24,35,90,91)$. The risk factors and associations identified in these studies may result from the inclusion of a proportion of individuals with ID. Alternatively, our results 
may be used to argue that intellectual functioning, as measured by WASI or otherwise, may be less useful when accounting for differences in clinical features and everyday functioning in patients with SUD.

\section{Strengths and Limitations}

The current cohort was recruited from a multitude of specialized and diversified SUD rehabilitation services including both inand out-patient units targeting different patient groups with regard to type and severity of comorbid psychiatric disorders, the severity of substance use, and degree of social adjustment and functioning, as well as the stage of the rehabilitation process. The universal access to health care in Norway allows the collection of a more comprehensive sample relative to countries where care is privatized and costly. Thus, the findings of the current study cannot necessarily be generalized to a specific clinical population (e.g., in-patients), but do elucidate the general state of intellectual functioning and associated clinical features among patients with pSUD.

Most previous studies investigated the clinical features of individuals with substance use among patients already identified as having ID (IQ < 70) or MBID (IQ= 50-85) (2). To the authors knowledge, this study is the first to examine the prevalence rates and associated demographic and clinical factors in individuals with previous unidentified BIF (IQ $=70-85)$ in both in- and outpatients receiving mainstream SUD services for polysubstance abuse. The current study's main findings are consistent with the few other studies from a SUD population, who identify an overrepresentation of impaired intellectual function among patients with SUD $(24,29)$. The current study adds on to these results by controlling for the effect of age, gender, years of education, age of onset of substance use, history of injecting drugs and satisfaction with life, in the analysis of the association between BIF and psychological distress.

The main limitation of this study concerns the representativeness of the Norwegian WASI test norms. Previous studies have shown that WASI tends to overestimate the FSIQ IQ level in Norwegian samples $(92,93)$, which may have led to the underestimation of the prevalence rate of BIF in the current study. In addition, the clinical differences between the BIF and non-BIF groups in the sample may have been masked if a skewed cut-of value of BIF have led to inclusion of non-BIF patients within the BIF group. Furthermore, WASI has not explicitly been validated for patients with SUD with a high level of psychological distress, which may also have affected the results of the present study. Finally, the STAYER cohort was recruited using convenience sampling in a clinical setting, which is vulnerable to ascertainment biases by undersampling patients with lower intellectual functioning, low motivation for change and lower-functioning patients with BIF.

\section{Clinical Implications}

BIF among patients with SUD is common. Screening for intellectual functioning should therefore always be considered as part of the clinical practice, and treatment programs should account for a significant sub-population of patients with cooccuring SUD and intellectual impairments.

Clinicians should not only be wary of elevated levels of psychological distress in patients with SUD (54), but also that BIF may represent a potential added risk factor for detrimental treatment outcomes, drug-seeking behavior and relapse. Studies aimed at examining potential factors that mediate and moderate the relationship between psychological distress and intellectual functioning are therefore strongly warranted.

The current study could not establish a relationship between BIF status and social adjustment, which further highlights the importance of including data pertaining to everyday functioning in the assessment and diagnosis of ID, as well as the classification of borderline intellectual disability. Conjointly, measurements of general intellectual functioning may, to a lesser degree, predict social adjustment in patients with SUD. Furthermore, the associated risk factors as well as the long-term rehabilitation trajectories and prognosis of the co-occurrence of SUD and BIF are mostly unknown and warrant further investigation.

\section{DATA AVAILABILITY STATEMENT}

The raw data supporting the conclusions of this article will be made available by the authors, without undue reservation.

\section{ETHICS STATEMENT}

The studies involving human participants were reviewed and approved by Regional Ethics Committee (REK 2011/1877). The patients/participants provided their written informed consent to participate in this study.

\section{AUTHOR CONTRIBUTIONS}

$\mathrm{JH}, \mathrm{EH}$, and AE: conceptualized and designed the study. $\mathrm{JH}$ : wrote the first draft and revised the manuscript. $\mathrm{JH}$ and $\mathrm{AE}$ : performed the analyses. $\mathrm{AE}, \mathrm{EH}, \mathrm{KB}$, and $\mathrm{AL}$ : made critical revisions of the manuscript. AE and AL: supervised the study. All authors contributed to the article and approved the submitted version.

\section{FUNDING}

The Western Norway Regional Health Authority, Strategic Initiative for Substance Use Research [912003], and the Department of Research and Education, Division of Psychiatry, Stavanger University Hospital, funded this research.

\section{ACKNOWLEDGMENTS}

The authors would like to extend their sincere gratitude to the participants in STAYER and the staff of the participating clinical services, the KORFOR staff, and, in particular, Thomas Solgård Svendsen, Anne-Lill Mjølhus Njaa, and Janne Aarstad, who collected all the data. 


\section{REFERENCES}

1. Didden R. Substance use and abuse in individuals with mild intellectual disability or borderline intellectual functioning: an introduction to the special section. Res Dev Disabil. (2017) 63:95-8. doi: 10.1016/j.ridd.2017.02.001

2. van Duijvenbode N, VanDerNagel JEL. A Systematic review of substance use (disorder) in individuals with mild to borderline intellectual disability. Eur Addict Res. (2019) 25:263-82. doi: 10.1159/000501679

3. Deary IJ, Whiteman MC, Starr JM, Whalley LJ, Fox HC. The impact of childhood intelligence on later life: following up the Scottish mental surveys of 1932 and 1947. J Pers Soc Psychol. (2004) 86:130-47. doi: 10.1037/0022-3514.86.1.130

4. Peltopuro M, Ahonen T, Kaartinen J, Seppälä H, Närhi V. Borderline intellectual functioning: a systematic literature review. Intellect Dev Disabil. (2014) 52:419-43. doi: 10.1352/1934-9556-52.6.419

5. Sternberg RJ, Grigorenko EL, Bundy DA. The predictive value of IQ. Merrill Palmer Q. (2001) 47:1-41. doi: 10.1353/mpq.2001.0005

6. Chen C-Y, Lawlor JP, Duggan AK, Hardy JB, Eaton WW. Mild cognitive impairment in early life and mental health problems in adulthood. Am J Public Health. (2006) 96:1772-8. doi: 10.2105/AJPH.2004.057075

7. Didden R, Embregts P, van der Toorn M, Laarhoven N. Substance abuse, coping strategies, adaptive skills and behavioral and emotional problems in clients with mild to borderline intellectual disability admitted to a treatment facility: a pilot study. Res Dev Disabil. (2009) 30:92732. doi: 10.1016/j.ridd.2009.01.002

8. Emerson E, Einfeld S, Stancliffe RJ. The mental health of young children with intellectual disabilities or borderline intellectual functioning. Soc Psychiatry Psychiatr Epidemiol. (2010) 45:579-87. doi: 10.1007/s00127-009-0100-y

9. Gigi K, Werbeloff N, Goldberg S, Portuguese S, Reichenberg A, Fruchter $\mathrm{E}$, et al. Borderline intellectual functioning is associated with poor social functioning, increased rates of psychiatric diagnosis and drug use - a cross sectional population based study. Eur Neuropsychopharmacol. (2014) 24:1793-7. doi: 10.1016/j.euroneuro.2014.07.016

10. Hassiotis A, Strydom A, Hall I, Ali A, Lawrence-Smith G, Meltzer H, et al. Psychiatric morbidity and social functioning among adults with borderline intelligence living in private households. J Intellect Disabil Res. (2008) 52:95106. doi: 10.1111/j.1365-2788.2007.01001.x

11. Seltzer MM, Floyd F, Greenberg J, Lounds J, Lindstrom M, Hong J. Life course impacts of mild intellectual deficits. Am J Ment Retard. (2005) 110:45168. doi: 10.1352/0895-8017(2005)110451:LCIOMI2.0.CO;2

12. Zammit S, Allebeck P, David AS, Dalman C, Hemmingsson T, Lundberg I, et al. A longitudinal study of premorbid IQ score and risk of developing schizophrenia, bipolar disorder, severe depression, and other nonaffective psychoses. Arch Gen Psychiatry. (2004) 61:354-60. doi: 10.1001/archpsyc.61.4.354

13. Salvador-Carulla L, García-Gutiérrez JC, Ruiz Gutiérrez-Colosía M, ArtigasPallarès J, García Ibáñez J, González Pérez J, et al. Borderline intellectual functioning: consensus and good practice guidelines. Rev Psiquiatr Salud Ment. (2013) 6:109-20. doi: 10.1016/j.rpsmen.2012.12.002

14. Hassiotis A. Borderline intellectual functioning and neurodevelopmental disorders: prevalence, comorbidities and treatment approaches. Adv Ment Health Intellect Disabil. (2015) 9:275-83. doi: 10.1108/AMHID-06-2015-0028

15. Wieland J, Zitman FG. It is time to bring borderline intellectual functioning back into the main fold of classification systems. BJPsych Bull. (2016) 40:2046. doi: 10.1192/pb.bp.115.051490

16. American Psychiatric Association. Diagnostic and Statistical Manual of Mental Disorders (DSM-5®). Arlington, VA: American Psychiatric Pub (2013). doi: 10.1176/appi.books.9780890425596

17. World Health Organization. The ICD-10 Classification of Mental and Behavioural Disorders: Clinical Descriptions and Diagnostic Guidelines. Geneva: World Health Organization (1992).

18. Ferrari M. Borderline intellectual functioning and the intellectual disability construct. Intellect Dev Disabil. (2009) 47:3869. doi: 10.1352/1934-9556-47.5.386

19. Melby L, Indredavik MS, Løhaugen G, Brubakk AM, Skranes J, Vik T. Is there an association between full IQ score and mental health problems in young adults? A study with a convenience sample. BMC Psychol. (2020) 8:7. doi: 10.1186/s40359-020-0372-2
20. Nouwens PJG, Lucas R, Embregts PJCM, van Nieuwenhuizen C. In plain sight but still invisible: a structured case analysis of people with mild intellectual disability or borderline intellectual functioning. J Intellect Dev Disabil. (2017) 42:36-44. doi: 10.3109/13668250.2016.1178220

21. Snell ME, Luckasson R, Borthwick-Duffy WS, Bradley V, Buntinx WHE, Coulter DL, et al. Characteristics and needs of people with intellectual disability who have higher IQs. Intellect Dev Disabil. (2009) 47:22033. doi: 10.1352/1934-9556-47.3.220

22. Wieland J, Kapitein-de Haan S, Zitman FG. Psychiatric disorders in outpatients with borderline intellectual functioning: comparison with both outpatients from regular mental health care and outpatients with mild intellectual disabilities. Can J Psychiatry. (2014) 59:213-9. doi: 10.1177/070674371405900406

23. Blume AW, Alan Marlatt G. The role of executive cognitive functions in changing substance use: what we know and what we need to know. Ann Behav Med. (2009) 37:117-25. doi: 10.1007/s12160-009-9093-8

24. Luteijn I, Didden R, VanDerNagel J. Individuals with mild intellectual disability or borderline intellectual functioning in a forensic addiction treatment center: prevalence and clinical characteristics. Adv Neurodevelopmental Disord. (2017) 1:24051. doi: 10.1007/s41252-017-0031-7

25. Bates ME, Pawlak AP, Tonigan JS, Buckman JF. Cognitive impairment influences drinking outcome by altering therapeutic mechanisms of change. Psychol Addict Behav. (2006) 20:241-53. doi: 10.1037/0893-164X.20.3.241

26. Aharonovich E, Hasin DS, Brooks AC, Liu X, Bisaga A, Nunes EV. Cognitive deficits predict low treatment retention in cocaine dependent patients. Drug Alcohol Depend. (2006) 81:313-22. doi: 10.1016/j.drugalcdep.2005.08.003

27. Brorson HH, Ajo Arnevik E, Rand-Hendriksen K, Duckert F. Drop-out from addiction treatment: a systematic review of risk factors. Clin Psychol Rev. (2013) 33:1010-24. doi: 10.1016/j.cpr.2013.07.007

28. Sømhovd M, Hagen E, Bergly T, Arnevik EA. The Montreal Cognitive Assessment as a predictor of dropout from residential substance use disorder treatment. Heliyon. (2019) 5:e01282. doi: 10.1016/j.heliyon.2019.e01282

29. Braatveit $\mathrm{K}$, Torsheim $\mathrm{T}$, Hove $\mathrm{O}$. The prevalence and characteristics of intellectual and borderline intellectual disabilities in a sample of inpatients with substance use disorders: preliminary clinical results. J Ment Health Res Intellect Disabil. (2018) 11:1-18. doi: 10.1080/19315864.2018.1469701

30. Taggart L, McLaughlin D, Quinn B, McFarlane C. Listening to people with intellectual disabilities who misuse alcohol and drugs. Health Soc Care Community. (2007) 15:360-8. doi: 10.1111/j.1365-2524.2007.00691.x

31. Fals-Stewart W. Ability of counselors to detect cognitive impairment among substance-abusing patients: an examination of diagnostic efficiency. Exp Clin Psychopharmacol. (1997) 5:39-50. doi: 10.1037/1064-1297.5.1.39

32. Gosens LCF, Otten R, Didden R, Poelen EAP. Evaluating a personalized treatment for substance use disorder in people with mild intellectual disability or borderline intellectual functioning: a study protocol of a multiple baseline across individuals design. Contemp Clin Trials Commun. (2020) 19:100616. doi: 10.1016/j.conctc.2020.100616

33. Knekt $\mathrm{P}$, Saari $\mathrm{T}$, Lindfors $\mathrm{O}$. Intelligence as a predictor of outcome in short- and long-term psychotherapy. Psychiatry Res. (2014) 220:101927. doi: $10.1016 /$ j.psychres.2014.10.011

34. Mathiassen B, Brøndbo $\mathrm{PH}$, Waterloo $\mathrm{K}$, Martinussen $\mathrm{M}$, Eriksen $\mathrm{M}$ Hanssen-Bauer K, et al. IQ as a moderator of outcome in severity of children's mental health status after treatment in outpatient clinics. Child Adolesc Psychiatry Ment Health. (2012) 6:22. doi: 10.1186/1753-2000-6-22

35. VanDerNagel JEL, Kiewik M, Postel MG, van Dijk M, Didden R, Buitelaar $\mathrm{JK}$, et al. Capture recapture estimation of the prevalence of mild intellectual disability and substance use disorder. Res Dev Disabil. (2014) 35:80813. doi: 10.1016/j.ridd.2014.01.018

36. Carroll Chapman SL, Wu L-T. Substance abuse among individuals with intellectual disabilities. Res Dev Disabil. (2012) 33:114756. doi: 10.1016/j.ridd.2012.02.009

37. Bhalla IP, Stefanovics EA, Rosenheck RA. Clinical epidemiology of single versus multiple substance use disorders: polysubstance use disorder. Med Care. (2017) 55:S24-32. doi: 10.1097/MLR.0000000000000731

38. McCabe SE, West BT, Jutkiewicz EM, Boyd CJ. Multiple DSM-5 substance use disorders: a national study of US adults. Hum Psychopharmacol Clin Exp. (2017) 32:e2625. doi: 10.1002/hup.2625 
39. Brooner RK, King VL, Kidorf M, Schmidt CW Jr, Bigelow GE. Psychiatric and substance use comorbidity among treatment-seeking opioid abusers. Arch Gen Psychiatry. (1997) 54:71-80. doi: 10.1001/archpsyc.1997.01830130077015

40. Choi NG, DiNitto DM. Older marijuana users in substance abuse treatment: treatment settings for marijuana-only versus polysubstance use admissions. J Subst Abuse Treat. (2019) 105:28-36. doi: 10.1016/j.jsat.2019.07.016

41. Palamar JJ, Le A, Mateu-Gelabert P. Not just heroin: extensive polysubstance use among US high school seniors who currently use heroin. Drug Alcohol Depend. (2018) 188:377-84. doi: 10.1016/j.drugalcdep.2018.05.001

42. Staines GL, Magura S, Foote J, Deluca A, Kosanke N. Polysubstance use among alcoholics. J Addict Dis. (2001) 20:53-69. doi: 10.1300/J069v20n04_06

43. Timko C, Han X, Woodhead E, Shelley A, Cucciare MA. Polysubstance use by stimulant users: health outcomes over three years. J Stud Alcohol Drugs. (2018) 79:799-807. doi: 10.15288/jsad.2018.79.799

44. Erga A, Honsi A, Anda L, Nesvag S, Hesse M, Hagen E. Trajectories of psychological distress during recovery from polysubstance use disorder. Addict Res Theory. (2020) 29:64-71. doi: 10.1080/16066359.2020.1730822

45. Preti E, Prunas A, Ravera F, Madeddu F. Polydrug abuse and personality disorders in a sample of substance-abusing inpatients. Ment Health Subst Use Dual Diagn. (2011) 4:256-66. doi: 10.1080/17523281.2011.577751

46. Andreas JB, Lauritzen G, Nordfjærn T. Co-occurrence between mental distress and poly-drug use: a ten year prospective study of patients from substance abuse treatment. Addict Behav. (2015) 48:71-8. doi: 10.1016/j.addbeh.2015.05.001

47. Booth BM, Curran G, Han X, Wright P, Frith S, Leukefeld C, et al. Longitudinal relationship between psychological distress and multiple substance use: results from a three-year multisite naturalhistory study of rural stimulant users. J Stud Alcohol Drugs. (2010) 71:258-67. doi: 10.15288/jsad.2010.71.258

48. Martinotti G, Carli V, Tedeschi D, di Giannantonio M, Janiri L, Sarchiapone M. Mono- and polysubstance dependent subjects differ on social factors, childhood trauma, personality, suicidal behaviour, and comorbid Axis I diagnoses. Addict Behav. (2009) 34:790-3. doi: 10.1016/j.addbeh.2009.04.012

49. Smith GW, Farrell M, Bunting BP, Houston JE, Shevlin M. Patterns of polydrug use in Great Britain: findings from a national household population survey. Drug Alcohol Depend. (2011) 113:222-8. doi: 10.1016/j.drugalcdep.2010.08.010

50. White A, Chan GCK, Quek L-H, Connor JP, Saunders JB, Baker P, et al. The topography of multiple drug use among adolescent Australians: findings from the National Drug Strategy Household Survey. Addict Behav. (2013) 38:2068-73. doi: 10.1016/j.addbeh.2013.01.001

51. Selby MJ, Azrin RL. Neuropsychological functioning in drug abusers. Drug Alcohol Depend. (1998) 50:39-45. doi: 10.1016/S0376-8716(98)00002-7

52. Quek LH, Chan GCK, White A, Connor JP, Baker PJ, Saunders JB, et al. Concurrent and simultaneous polydrug use: latent class analysis of an Australian nationally representative sample of young adults. Front Public Health. (2013) 1:61. doi: 10.3389/fpubh.2013.00061

53. Flynn PM, Brown BS. Co-occurring disorders in substance abuse treatment: issues and prospects. J Subst Abuse Treat. (2008) 34:36-47. doi: 10.1016/j.jsat.2006.11.013

54. Andersson HW, Steinsbekk A, Walderhaug E, Otterholt E, Nordfjærn T. Predictors of dropout from inpatient substance use treatment: a prospective cohort study. Subst Abuse. (2018) 12:1178221818760551. doi: 10.1177/1178221818760551

55. Daigre C, Perea-Ortueta M, Berenguer M, Esculies O, Sorribes-Puertas M, Palma-Alvarez R, et al. Psychiatric factors affecting recovery after a long term treatment program for substance use disorder. Psychiatry Res. (2019) 276:283-9. doi: 10.1016/j.psychres.2019.05.026

56. Agosti V, Nunes E, Ocepeck-welikson K. Patient factors related to early attrition from an outpatient cocaine research clinic. Am J Drug Alcohol Abuse. (1996) 22:29-39. doi: 10.3109/00952999609001643

57. Simşek M, Dinç M, Ögel K. Determinants of the addiction treatment drop-out rates in an addiction counseling centre: a cross-sectional study. Psychiatry Clin Psychopharmacol. (2019) 29:446-54. doi: 10.1080/24750573.2018.1505283

58. Connor JP, Gullo MJ, White A, Kelly AB. Polysubstance use: diagnostic challenges, patterns of use and health. Curr Opin Psychiatry. (2014) 27:26975. doi: 10.1097/YCO.0000000000000069
59. Williamson A, Darke S, Ross J, Teesson M. The effect of persistence of cocaine use on 12-month outcomes for the treatment of heroin dependence. Drug Alcohol Depend. (2006) 81:293-300. doi: 10.1016/j.drugalcdep.2005.08.010

60. Hagen E, Erga AH, Hagen KP, Nesvåg SM, McKay JR, Lundervold AJ, et al. Assessment of executive function in patients with substance use disorder: a comparison of inventory- and performance-based assessment. J Subst Abuse Treat. (2016) 66:1-8. doi: 10.1016/j.jsat.2016.02.010

61. Svendsen TS, Erga AH, Hagen E, McKay JR, Njå ALM, Årstad J, et al. How to maintain high retention rates in long-term research on addiction: a case report. J Soc Work Pract Addict. (2017) 17:37487. doi: 10.1080/1533256X.2017.1361831

62. Miller L. Neuropsychological assessment substance abusers: review and recommendations. J Subst Abuse Treat. (1985) 2:5-17. doi: 10.1016/0740-5472(85)90017-0

63. Center for Alcohol \& Drug Research Helse Vest. National Quality Register for the Treatment of Harmful Substance Use or Addiction. (2018) [October 7, 2020]. Available online at: https://helse-stavanger.no/seksjon/kvarus/ Documents/KvarusEngelsk.pdf (accessed June 28, 2021).

64. Wechsler D. Wechsler Abbreviated Scale of Intelligence WASI: Manual. San Antonio, TX: Pearson/PsychCorp (1999). doi: 10.1037/t15170-000

65. Diener E, Emmons RA, Larsen RJ, Griffin S. The satisfaction with life scale. J Pers Assess. (1985) 49:71-5. doi: 10.1207/s15327752jpa4901_13

66. Pavot W, Diener E. The satisfaction with life scale and the emerging construct of life satisfaction. J Posit Psychol. (2008) 3:137-52. doi: 10.1080/17439760701756946

67. Lucas-Carrasco R, Salvador-Carulla L. Life satisfaction in persons with Intellectual Disabilities. Res Dev Disabil. (2012) 33:1103-9. doi: 10.1016/j.ridd.2012.02.002

68. Derogatis LR. SCL-90-R: Symptom Checklist-90-R: Administration, Scoring \& Procedures Manual. Minneapolis, Minn.: Pearson (1994).

69. Kellett SC, Beail N, Newman DW, Mosley E. Indexing psychological distress in people with an intellectual disability: use of the symptom checklist-90-R. J Appl Res Intellect Disabil. (1999) 12:323-34. doi: 10.1111/j.1468-3148.1999.tb00088.x

70. Bergly T, Nordfjærn T, Hagen R. The dimensional structure of SCL-90-R in a sample of patients with substance use disorder. J Subst Use. (2013) 19:257-61. doi: 10.3109/14659891.2013.790494

71. Peduzzi P, Concato J, Kemper E, Holford TR, Feinstein AR. A simulation study of the number of events per variable in logistic regression analysis. $J$ Clin Epidemiol. (1996) 49:1373-9. doi: 10.1016/S0895-4356(96)00236-3

72. Jorm AF, Windsor TD, Dear KBG, Anstey KJ, Christensen H, Rodgers B. Age group differences in psychological distress: the role of psychosocial risk factors that vary with age. Psychol Med. (2005) 35:1253-63. doi: 10.1017/S0033291705004976

73. Batty GD, Mortensen EL, Osler M. Childhood IQ in relation to later psychiatric disorder: evidence from a Danish birth cohort study. $\mathrm{Br} J$ Psychiatry. (2005) 187:180-1. doi: 10.1192/bjp.187.2.180

74. Höijer I, Ilonen T, Löyttyniemi E, Salokangas RKR. Neuropsychological performance in patients with substance use disorder with and without mood disorders. Nord J Psychiatry. (2020) 74:44452. doi: 10.1080/08039488.2020.1734079

75. Rajput S, Hassiotis A, Richards M, Hatch SL, Stewart R. Associations between IQ and common mental disorders: the 2000 British National Survey of Psychiatric Morbidity. Eur Psychiatry. (2011) 26:390-5. doi: 10.1016/j.eurpsy.2010.07.002

76. Teasdale TW, Antal K. Psychological distress and intelligence in young men. Pers Individ Dif. (2016) 99:336-9. doi: 10.1016/j.paid.2016.05.016

77. Gale CR, Hatch SL, Batty GD, Deary IJ. Intelligence in childhood and risk of psychological distress in adulthood: the 1958 National Child Development Survey and the 1970 British Cohort Study. Intelligence. (2009) 37:5929. doi: 10.1016/j.intell.2008.09.002

78. Lohr JB, May T, Caligiuri MP. Quantitative assessment of motor abnormalities in untreated patients with major depressive disorder. J Affect Disord. (2013) 146:84-90. doi: 10.1016/j.jad.2012.08.043

79. Tsourtos G, Thompson JC, Stough C. Evidence of an early information processing speed deficit in unipolar major depression. Psychol Med. (2002) 32:259-65. doi: 10.1017/S0033291701005001 
80. Marazziti D, Consoli G, Picchetti M, Carlini M, Faravelli L. Cognitive impairment in major depression. Eur J Pharmacol. (2010) 626:836. doi: 10.1016/j.ejphar.2009.08.046

81. Deary IJ, Strand S, Smith P, Fernandes C. Intelligence and educational achievement. Intelligence. (2007) 35:13-21. doi: 10.1016/j.intell.2006.02.001

82. Tommasi M, Pezzuti L, Colom R, Abad FJ, Saggino A, Orsini A. Increased educational level is related with higher IQ scores but lower g-variance: evidence from the standardization of the WAIS-R for Italy. Intelligence. (2015) 50:68-74. doi: 10.1016/j.intell.2015.02.005

83. Fergusson DM, Horwood LJ, Ridder EM. Show me the child at seven II: childhood intelligence and later outcomes in adolescence and young adulthood. J Child Psychol Psychiatry. (2005) 46:850-8. doi: 10.1111/j.1469-7610.2005.01472.x

84. Martins SS, Alexandre PK. The association of ecstasy use and academic achievement among adolescents in two U.S. national surveys. Addict Behav. (2009) 34:9-16. doi: 10.1016/j.addbeh.2008.07.022

85. Engberg J, Morral AR. Reducing substance use improves adolescents' school attendance. Addiction. (2006) 101:174151. doi: 10.1111/j.1360-0443.2006.01544.x

86. Lynskey $M$, Hall $\mathrm{W}$. The effects of adolescent cannabis use on educational attainment: a review. Addiction. (2000) 95:162130. doi: 10.1046/j.1360-0443.2000.951116213.x

87. Kessler RC, Foster CL, Saunders WB, Stang PE. Social consequences of psychiatric disorders, I: Educational attainment. Am J Psychiatry. (1995) 152:1026-32. doi: 10.1176/ajp.152.7.1026

88. Breslau J, Lane M, Sampson N, Kessler RC. Mental disorders and subsequent educational attainment in a US national sample. J Psychiatr Res. (2008) 42:708-16. doi: 10.1016/j.jpsychires.2008.01.016

89. Bohon C, Garber J, Horowitz J. Predicting school dropout and adolescent sexual behavior in offspring of depressed and nondepressed mothers. J Am Acad Child Adolesc Psychiatry. (2007) 46:15-24. doi: 10.1097/01.chi.0000246052.30426.6e
90. Luteijn I, VanDerNagel JEL, van Duijvenbode $\mathrm{N}$, de Haan HA, Poelen EAP, Didden R. Post-traumatic stress disorder and substance use disorder in individuals with mild intellectual disability or borderline intellectual functioning: a review of treatment studies. Res Dev Disabil. (2020) 105:103753. doi: 10.1016/j.ridd.2020.1 03753

91. van Duijvenbode N, VanDerNagel JEL, Didden R, Engels RCME, Buitelaar JK, Kiewik $M$, et al. Substance use disorders in individuals with mild to borderline intellectual disability: current status and future directions. Res Dev Disabil. (2015) 38:319-28. doi: 10.1016/j.ridd.2014. 12.029

92. Bosnes O. Norsk versjon av Wechsler Abbreviated Scale of Intelligence: Hvor godt er samsvaret mellom WASI og norsk versjon av Wechsler Adult Intelligence Scale-III? [The Norwegian version of Wechsler Abbreviated Scale of Intelligence (WASI): Do scores on the WASI correspond with scores on the Norwegian version of the Wechsle Adult Intelligence Scale- III (WAIS-III)?]. Tidsskrift for Norsk Psykologforening. (2009) 46:564-8.

93. Siqveland J, Dalsbø TK, Harboe I, Leiknes KA. Psychometric Evaluation of the Norwegian Version of the Wechsler Abbreviated Scale of Intelligence (WASI). Oslo: Norwegian (2014). p. 8281219025.

Conflict of Interest: The authors declare that the research was conducted in the absence of any commercial or financial relationships that could be construed as a potential conflict of interest.

Copyright (c) 2021 Hetland, Braatveit, Hagen, Lundervold and Erga. This is an open-access article distributed under the terms of the Creative Commons Attribution License (CC BY). The use, distribution or reproduction in other forums is permitted, provided the original author(s) and the copyright owner(s) are credited and that the original publication in this journal is cited, in accordance with accepted academic practice. No use, distribution or reproduction is permitted which does not comply with these terms. 